\title{
THE GREEN SYNTHESIS, CHARACTERIZATION AND EVALUATION OF ANTIOXIDANT AND ANTIMICROBIAL EFFICACY OF SILVER AND GOLD NANOSPHERES SYNTHESIZED USING WHEAT BRAN
}

\author{
SONIKA GUPTA, O. P. JANGIR, MUKESH SHARMA \\ Department of Biotechnology, MVG University, Dhand, Tehsil-Amer, Jaipur, Rajasthan, India. Email: guptasonika41@gmail.com \\ Received: 28 June 2016, Revised and Accepted: 04 July 2016
}

\section{ABSTRACT}

Objective: In the present scenario, biogenic production of gold nanoparticles (AuNPs) and silver nanoparticles (AgNPs) has evoked considerable interest in terms of their diverse biomedical applications because of their extremely small size and large surface to volume ratio. Hence, the aims of the current study were to use the plant extract for the biosynthesis of AgNPs and AuNPs and to evaluate their antibacterial and antioxidant activity in vitro.

Methods: First, aqueous silver nitrate and chloroauric acid solutions have been treated with wheat bran extract; a reduction of the silver nitrate and chloroaurate ions is witnessed resulting in the formation of highly stable AgNPs and AuNPs in solution. Characterization of synthesized silver and gold nanospheres is made using ultraviolet visible (UV-VIS), scanning electron microscopy, and transmission electron microscopy analysis. The free radical scavenging potential has been also investigated using 2,2-diphenylpicrylhydrazyl (DPPH) assay, examined by a UV-VIS spectrophotometer Antimicrobial efficacy against dental disease-causing pathogens - Staphylococcus aureus (microbial type culture collection [MTCC] 7443) and Streptococcus mutans (MTCC 497) was tested using agar diffusion method.

Results and Conclusion: Characterization of silver and gold nanospheres indicated that they ranged from 30-55 nm to 45-70 nm in size, respectively. The synthesized AgNPs and AuNPs efficiently inhibited the growth of respective pathogens. It is found that AgNPs and AuNPs exhibited exceptionally effective antimicrobial potential-compared to wheat bran extract alone. In DPPH scavenging activity, the percentage of inhibition increases with increase in the concentration of synthesized Ag and Au NPs proved that synthesized NPs possessed high antioxidant activity. It could be concluded that these nanospheres can be act as a potent antioxidant and antimicrobial agents for commercial application.

Key words: AuNPs, AgNPs, Wheat Bran, Antioxidant Activity, Antibacterial Activity

(C) 2016 The Authors. Published by Innovare Academic Sciences Pvt Ltd. This is an open access article under the CC BY license (http://creativecommons. org/licenses/by/4. 0/) DOI: http://dx.doi.org/10.22159/ajpcr.2016.v9i6.13758

\section{INTRODUCTION}

Nanotechnology has been entitled as the next industrial revolution and is centered on the production of nanomaterial or particles with as a minimum of one dimension between 1 and $100 \mathrm{~nm}[1,2]$. Unique physicochemical characteristics of metal nanoparticles (NPs) including catalytic activity, electronic, optical, magnetic, and antibacterial properties differ from the bulk metals when the particle size decreases, specifically at sizes between 1 and $100 \mathrm{~nm} \mathrm{[3,2],} \mathrm{and} \mathrm{these} \mathrm{novel}$ properties have gaining the interest of scientists and made NPs attractive for research in various fields.

Recent studies showed that NPs those made from noble metals, silver (Ag) [4], and gold ( $\mathrm{Au}$ ) exhibit unique antimicrobial property. Silver is known for its bactericidal effects because it is safe and non-toxic to animal cells and extremely toxic to bacteria [5,6]. AgNPs are one of the most commonly used nanomaterials as they have antioxidant and antimicrobial properties. The most extensively used applications of AgNPs and AuNPs are in coating or embedding for medical purposes [7] and to prevent the infection of burns and wounds [8]. Similarly, progress has been achieved in the evaluation of properties of Au NPs for the control of pathogenic bacteria indicator strains as well as to scavenge radicals formed during cellular metabolism. It was reported that high aspect ratio $\mathrm{Au}$ nanorods can act as an effective antioxidant and antibacterial agent and it makes the NPs as the most promising candidate for biomedical applications [9]. Thus, nanoscale silver and gold particles represent a new era of cost-effective antimicrobial and antioxidant technologies.

Numerous procedures have confirmed that NPs can be synthesized using chemical and physical techniques, but it is mandatory to discover an alternative method due to the fact of usage of an enormous amount of toxic chemicals and high-temperature conditions in chemical and physical methods [10]. The aims of green synthesis or biosynthesis of NPs are - an eco-friendly fabrication and uses of extracts from plants, organisms [i.e., biomolecules], and non-toxic reductants for particle stability [11]

Synthesis of NPs by green chemistry approach lay emphasis on the usage of microorganisms, enzyme and plant or plant extract, makes the process reliable, simple, and nontoxic and has been recommended as potential eco-friendly substitutes to chemical and physical methods $[12,13]$. Thus, researchers in the last years have turned to biological systems for NP synthesis [14].

Wheat (Triticum aestivum) is an earliest known food crop which belongs to the family Poaceae, cultivated since the beginning of human civilization and positions first among world cereal crops. Whole-grain wheat contain three layers; $80-85 \%$ endosperm, $10-14 \%$ bran, and 2.5-3\% germ [15]. The bran layers enclose the endosperm and are abundant in vitamins, minerals protein, and large amounts of insoluble dietary fiber [16].

Wheat bran consists of aleurone and pericarp and is the hard outer layer of wheat grain. Wheat bran is produced in enormous quantities as a major by-product of the milling process for the production of white wheat flour. Due to its enormous production in the milling process, wheat bran has also been considered to have a potential as a valuable and versatile feedstock for future biorefineries [17]. It is not only the good supplier of dietary fibers in addition to their physiological functions but it also contains a significant amount of natural antioxidants [18]. A recent study of Swiss red wheat grain and fractions indicated that phenolic antioxidants are concentrated in the aleurone fraction of wheat bran [19]. The antioxidants play a chemoprotective 
key role in human against the risk of oxidative stress-related diseases such as cancer and cardiovascular diseases [20].

Keeping this in view, we have discovered for the first time the green synthesis of silver and gold nanospheres using wheat bran extract and an investigation is focussed to evaluate the potential use of silver and gold nanospheres as an antibacterial and antioxidant agent against dental disease-causing pathogens, namely Staphylococcus aureus (microbial type culture collection [MTCC] 7443) and Streptococcus mutans (MTCC 497).

\section{METHODS}

Wheat bran used for the preparation of the extract was procured from the local supermarket. Silver nitrate and chloroauric acid were supplied by Sigma-Aldrich Chemicals. The bacterial strains used in this work were obtained from IMTECH, Chandigarh, India. For anti-oxidative studies, all chemicals and reagents used in the study were of analytical grade.

\section{Preparation of sample extract}

About $5 \mathrm{~g}$ of wheat bran was accurately weighed, mixed in $100 \mathrm{ml}$ of double deionized water and heated over a water bath maintained at $60^{\circ} \mathrm{C}$ for 30 minutes. Wait for temperature to normal down. The extract obtained was filtered through muslin cloth and then centrifuged at $10,000 \mathrm{rpm}$ for 15 minutes. The supernatant was collected and used for the biosynthesis of gold NPs and AgNPs.

\section{Synthesis of AgNPs}

An aqueous solution of $1 \mathrm{mM}$ silver nitrate solution $\left(\mathrm{AgNO}_{3}\right)$ was prepared and used for further experiment. $10 \mathrm{ml}$ of wheat bran extract was mixed with $90 \mathrm{ml}$ of $\mathrm{AgNO}_{3}$ (1:9 ratio), and the resulting solution was incubated overnight at $50^{\circ} \mathrm{C}$ for the synthesis of AgNPs. The formation of AuNPs was confirmed by color change from colorless to reddish brown and by ultraviolet visible (UV-VIS) spectroscopy.

\section{Synthesis of AuNPs}

Wheat bran extract was mixed with aqueous solution of HAuCl4 (1 mM) in the ratio of $1: 1$, and the reaction volume was made up to $100 \mathrm{ml}$. The mixture solution was left overnight at $50^{\circ} \mathrm{C}$ for the synthesis of AuNPs and observed for change in color from colorless to wine red color.

\section{Characterization of biosynthesized AgNPs and AuNPs}

\section{UV-VIS spectroscopy}

UV-visible spectroscopy is used for monitoring the formation of NPs using wheat bran extract by measuring spectrum of the reaction mixture after diluting a small aliquot of the sample with deionized water. The measurements are recorded on UV-VIS dual beam spectrometer (Systonic 2203 Double Beam)

\section{Scanning electron microscopy (SEM)}

This study was undertaken to identify the size and shape of the NPs biosynthesized using wheat bran extract by SEM analyzer SEM-Zeiss machine. The sample was prepared by placing a drop of solution containing NPs on carbon coated copper grid; extra solution was removed using a blotting paper. Then, the film on the SEM grid was allowed to dry and the images of NPs were taken.

\section{Transmission electron microscopy (TEM)}

TEM is a technique of producing images of a sample by illuminating the sample with electronic radiation (under vacuum), and detecting the electrons that are transmitted through the sample. The 200KV highresolution TEM (TEM-FEI Tecnai G2 S-Twin) was used. TEM grid was prepared by placing a drop of the particle solution and drying under an IR lamp.

\section{Pharmacognostic evaluation of synthesized NPs}

Determination of free radical scavenging activity by 2,2-diphenylpicrylhydrazyl (DPPH) assay

Antioxidant activity of the synthesized NPs and standard was measured on the basis of the radical scavenging effect of the stable DPPH free radical.
Gallic acid was used as the standard in solutions ranging from 1 to 50 $\mu \mathrm{g} / \mathrm{ml}$. $0.135 \mathrm{mM}$ DPPH solution in methanol was prepared. Then, $2 \mathrm{ml}$ of this solution was mixed with $2 \mathrm{ml}$ of sample solutions (ranging from $50 \mu \mathrm{g} / \mathrm{ml}$ to $250 \mu \mathrm{g} / \mathrm{ml}$ ) and the standard solution to be tested separately. These solution mixtures were kept in the dark for 30 minutes, and optical density was recorded at $517 \mathrm{~nm}$ using an SEM-Zeiss spectrophotometer against methanol. The control was used is $2 \mathrm{ml}$ of methanol with $2 \mathrm{ml}$ of DPPH solution. The optical density was recorded and percentage of inhibition was calculated using the formula given below:

$\%$ of inhibition $=(A$ of control $-\mathrm{A}$ of test $) / \mathrm{A}$ of control $\times 100$, where $\mathrm{A}$ is absorbance

\section{Determination of antibacterial activity}

The in-vitro antimicrobial activity of Ag and Au NPs synthesized using wheat bran extract was determined on Muller and Hinton Agar (HiMedia Pvt., Ltd. Mumbai) using agar diffusion method. Test pathogens S. aureus (MTCC 7443) and S. mutans (MTCC 497) were spread on the test plates - Muller-Hinton agar for bacteria using sterile swabs. Sterile wells were prepared with the help of a sterile cork borer at aseptic conditions. Samples were added to the wells at aseptic conditions. The test plates were incubated and the zone of inhibition was taken as the activity of the extract against the organisms.

\section{RESULTS}

\section{Characterization of biosynthesized AgNPs and AuNPs}

Results indicated that change of reaction mixture's color from colorless to intense yellow was the evidence of reduction of silver ions into AgNPs using wheat bran extract. The UV-VIS spectra showed an absorption band at $448 \mathrm{~nm}$, confirmed the presence of Ag NPs. For AuNPs, the spectrophotometric study of bio-reduced dark brown colored reaction mixture through the range spectra $300-700 \mathrm{~nm}$ showed a maximum absorption at $551 \mathrm{~nm}$ which confirmed the presence of AuNP in the reaction mixture.

SEM and TEM analysis provided further insight into the morphology and size of the synthesized NPs. Experimental results revealed that the diameter of synthesized $\mathrm{Ag}$ and Au NPs ranged from 30 to $55 \mathrm{~nm}$ and 45-70 nm, respectively, and both were spherical in shape as shown in Figs. 1 and 2.

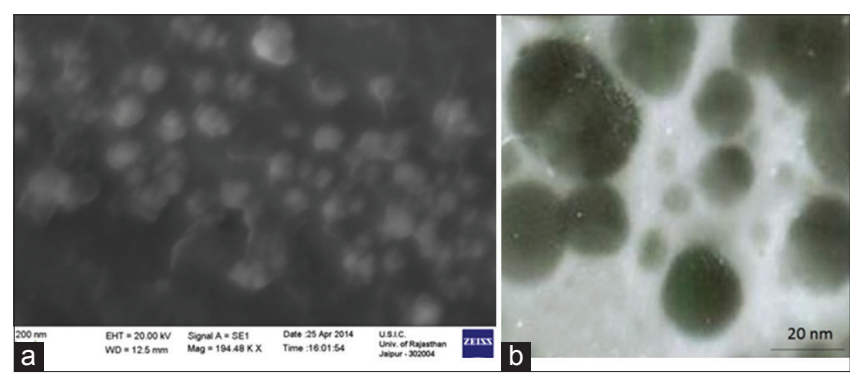

Fig. 1: Micrograph of biosynthesized silver nanospheres. (a) SEM image, (b) TEM image

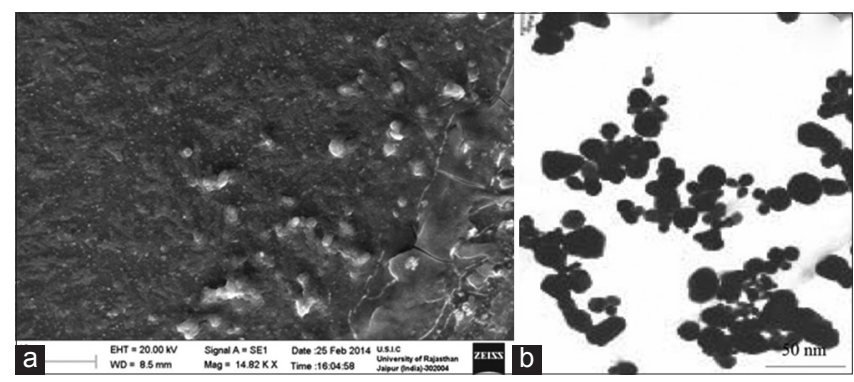

Fig. 2: Micrograph of biosynthesized gold nanospheres. (a) scanning electron microscopy image, (b) transmission electron microscopy image 
Pharmacognostic evaluation of synthesized NPs

The antioxidant activity of Ag and Au NPs was evaluated using DPPH scavenging assay. As shown in Table 1 and Fig. 3, the percentage of inhibition increases with increase in the concentration of synthesized $\mathrm{Ag}$ and $\mathrm{Au}$ NPs proved that synthesized NPs possessed high antioxidant activity which augmented in a dose-dependent manner.

The in-vitro antimicrobial activity of synthesized Ag and Au NP were carried out on two dental disease-causing pathogens - S. aureus (MTCC 7443) and $S$. mutans (MTCC 497). Biosynthesized AgNPs and AuNPs showed clear zone of inhibition as indicated in Fig. 4 against the pathogenic test bacteria. The results suggested that these 2 test bacteria were susceptible to the synthesized Ag and Au NPs of the wheat bran extracts.

\section{CONCLUSION}

The current study revealed that wheat bran extract is a reliable and eco-friendly source for biosynthesis of Ag and Au NPs. Here, we have

Table 1: DPPH free radical scavenging activity of biosynthesized silver and gold nanoparticles

\begin{tabular}{lllll}
\hline Sample & $\begin{array}{l}\text { Concentration } \\
\text { (ml) }\end{array}$ & $\begin{array}{l}\text { Average } \\
\text { absorbance }\end{array}$ & $\begin{array}{l}\text { inhibition } \\
\text { \% }\end{array}$ & IC $_{50}$ \\
\hline AgNP & 0.5 & 0.487 & 21.19 & 1.0879 \\
& 1.0 & 0.303 & 50.97 & \\
\multirow{2}{*}{ AuNP } & 1.5 & 0.210 & 66.01 & \\
& 0.5 & 0.529 & 14.40 & 0.92915 \\
& 1.0 & 0.349 & 43.53 & \\
\hline
\end{tabular}

Control absorbance=0.618. AuNP: Gold nanoparticle, AgNP: Silver nanoparticle

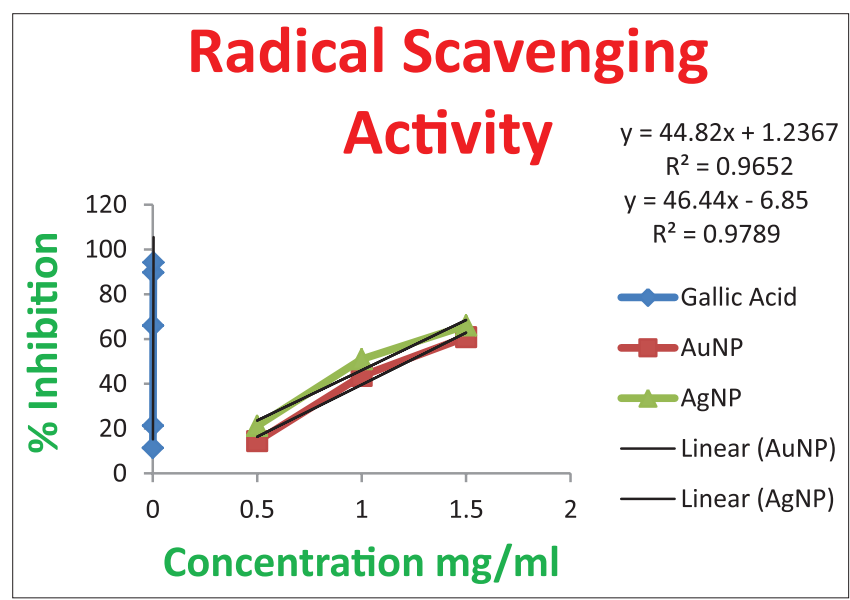

Fig. 3: Graphical representation of 2,2-diphenylpicrylhydrazyl scavenging activity of biosynthesized silver nanonspheres and gold nanonspheres

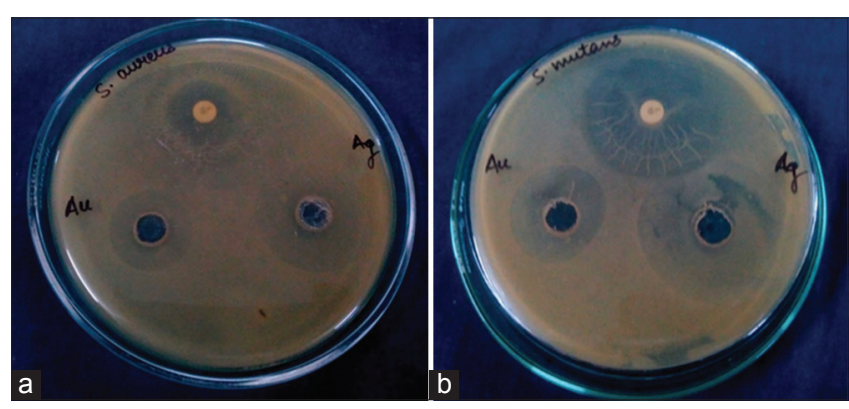

Fig. 4: The antibacterial effect of biosynthesized Silver and gold nanospheres on test organisms. (a) Staphylococcus aureus and,

(b) Streptococcus mutans reported a simple reproducible and cost-effective method for the synthesis of stable Ag and Au NPs using aqueous wheat bran extract as the reducing, stabilizing, and capping agent. This is the first study in which green synthesis of silver and gold nanorods is reported from wheat bran extract. The biologically synthesized AgNPs and AuNPs exhibited exceptional antioxidant potential and antimicrobial activity against S. aureus (MTCC 7443) and S. mutans (MTCC 497) - dental disease causing pathogens. Moreover, diameter of synthesized Ag and $\mathrm{Au}$ NPs ranged from 30-55 $\mathrm{nm}$ to $45-70 \mathrm{~nm}$, respectively, hence these NPs would be a more competent in the drug delivery process. Thus, summarizing all the outcomes, it can be concluded that Ag and $\mathrm{Au}$ nanospheres can act as an effective antibacterial and antioxidant agent thus making the NP as a substitute for the development of novel biomedical drugs in near future. Therefore, further studies are required to entirely characterize the molecular mechanisms associated with the antimicrobial and antioxidant activities of these NPs.

\section{REFERENCES}

1. ASTM International. Terminology for Nanotechnology. Wes Conshohocken, PA: ASTM International; 2006.

2. Moore MN. Do nanoparticles present ecotoxicological risks for the health of the aquatic environment? Environ Int 2006;32(8):967-76.

3. Niemeyer C. Nanoparticles, proteins, and nucleic acids: Biotechnology meets materials science. Angew Chem Int Ed 2001;40(22):4128-58.

4. Sharma VK, Yngard RA, Lin Y. Silver nanoparticles: Green synthesis and their antimicrobial activities. Adv Colloid Interface Sci 2009;145(1-2):83-96.

5. Kim JS, Kuk E, Yu KN, Kim JH, Park SJ, Lee HJ, et al. Antimicrobia effects of silver nanoparticles. Nanomed Nanotechnol Biol Med 2007;3(2):95-101.

6. Marambio-Jones C, Hoek EM. A review of the antibacterial effects of silver nanomaterials and potential implications for human health and the environment. J Nanopart Res 2010;12(5):1531-51.

7. Xu X, Yang Q, Bai J, Lu T, Li Y, Jing X. Fabrication of biodegradable electrospun poly(L-lactide-co-glycolide) fibers with antimicrobial nanosilver particles. J Nanosci Nanotechnol 2008;8:5066-70

8. Murphy CJ. Sustainability as a design criterion in nanoparticle synthesis and applications. J Mater Chem 2008;18:2173-6.

9. Djajadisastra J, Sutriyo C, Purnamasari P, Pujiyanto A. Antioxidan activity of gold nanoparticles using gum Arabic as a stabilizing agent. Int J Pharm Pharm Sci 2014;6(7):462-5

10. Kumar P, Roy I. Applications of gold nanoparticles in clinical medicine. Int J Pharm Pharm Sci 2016;8(7):11-6.

11. Nair B, Pradeep T. Coalescence of nanoclusters and formation of submicron crystallites assisted by Lactobacillus strains cryst. Growth Des 2002;2(4):293-8

12. Sathishkumar M, Sneha K, Yun YS. Immobilization of silver nanoparticles synthesized using Curcuma longa tuber powder and extract on cotton cloth for bactericidal activity. Bioresource Technol 2010;101(20):7958-65.

13. Roy N, Barik A. Green synthesis of silver nanoparticles using unexploited weed resources. Int J Nanotech Appl 2010;4(2):95-101.

14. Tsibakhashvil N, Kalabegishvili T, Gabunia V, Gintury E, Kuchava N, Bagdavadze N, et al. Synthesis of silver nanoparticles using bacteria. Nano Stud 2010;2:179-82.

15. Fardet A. New hypotheses for the health-protective mechanisms of whole-grain cereals: What is beyond fibre? Nutr Res Rev 2010;23:65-134.

16. Saulnier L, Sado PE, Brandland G, Charmet G, Guillon, F. Wheat arabinoxylans: Exploting variation in amount and composition to develop enhanced varieties. J Cereal Sci 2007;46(3):261-82.

17. Reisinger M, Tirpanalan O, Prückler M, Huber F, Kneifel W, Novalin S Wheat bran biorefinery - A detailed investigation on hydrothermal and enzymatic treatment. Bioresour Technol 2013;144:179-85.

18. Zhou K, Su L, Yu LL. Phytochemicals and antioxidant properties in wheat bran. J Agric Food Chem 2004;52(20):6108-14.

19. Zhou K, Laux JJ, Yu L. Comparison of Swiss red wheat grain and fractions for their antioxidant properties. J Agric Food Chem 2004;52(5):1118-23.

20. Sang $\mathrm{S}$, Ju J, Lambert JD, Lin Y, Hong J, Bose M, et al. Wheat bran oil and its fractions inhibit human colon cancer cell growth and intestinal tumorigenesis in Apc(min/) mice. J Agric Food Chem 2006;54(26):9792-7. 